\title{
Challenges Encountered in Compliance to Hand Hygiene in the Pediatric Department of a Hospital in Central Vietnam
}

\author{
Kevin B. H. Vo ${ }^{1}$, HuyTram N. Nguyen ${ }^{1}$, Binh Doan ${ }^{2}$, Quynh Kieu ${ }^{2}$, H. Ian Robins ${ }^{3 *}$ \\ ${ }^{1}$ University of Wisconsin - School of Medicine and Public Health, Madison, USA \\ ${ }^{2}$ Project Vietnam Foundation, Fountain Valley, California, USA \\ ${ }^{3}$ Department of Medicine, University of Wisconsin - School of Medicine and Public Health, Madison, USA \\ *Corresponding Author: H. Ian Robins MD PhD, Box 5664 Clinical Science Center, 600 Highland \\ Ave., Madison, WI 53792,USA. Email: hirobins@wisc.edu
}

\begin{abstract}
Background: Hand hygiene is a fundamental, but often overlooked, aspect in infection control. This project assessed the compliance for hand hygiene in the Pediatric Department of Quang Tri General Hospital $(Q T G H)$ located in Quang Tri Province, Vietnam and to identify opportunities for quality improvement.
\end{abstract}

Methods: Hand hygiene procedure, i.e., hand washing and alcohol based hand rubbing (ABHR), are based on the World Health Organization's guideline. An audit on hand hygiene compliance was done in the Pediatric Department inpatient wards and outpatient clinic. A survey was conducted to assess 22 health care staff's perceptions and attitudes on their hand hygiene procedure.

Findings: Hand rubbing supply was available in the Neonatal Intensive Care Unit (NICU) and outpatient clinic with an overall compliance rate of $76 \%$ (19 actions/25 opportunities). The outpatient clinic contributed the most to this result with 100\% compliance (15/15), while the NICU staff had a compliance of 40\% (4/10). The inpatient ward was noncompliant for ABHR and hand washing 100\% of the time. Hand washing was only practiced prior to entering the NICU. A survey was conducted showing that all the staff (100\%) was aware of the importance and procedure required for hand hygiene during patient care.

Conclusion: While the staff understood the importance of hand hygiene, there was low compliance. Accessibility to alcohol based solution and sink was not readily available, possibly contributing to this observation. Moving forward, equipping the staff with portable hand rubbing solution and implementing frequent inspections should improve compliance.

Keywords: quality improvement, hand hygiene, hand washing, protocol compliance, healthcare, Vietnam

\section{INTRODUCTION}

In a 1999 report from the Institute of Medicine, "To Err is Human", an estimated number of 44,000-98,000 Americans died every year because of preventable hospital errors [1]. Most errors were due to wound infection, which could have been prevented if physicians and other medical staff had washed their hands more frequently. Various reasons exist for why health care providers do not wash their hands before and after each patient encounter. Health care providers might be pressed for time. Another reason could be due to the lack of accessibility to sinks and hand washing equipment, which make hand washing an inconvenient procedure for many providers. Perception deficit could also play a role. Health care providers might think that they are washing their hands regularly, but they are not doing it as often as they perceive themselves to be[2].

Improper hand hygiene adherence is a worldwide problem. A study conducted on Intensive Care Units for 8 developing countries that are members of the International Nosocomial Infection Control Consortium found that compliance ranged from 20\% to $70 \%$. The overall rate of hand hygiene adherence was $50 \%$, which was similar to the rates of developed countries in Europe and the United States[3]. Noncompliance for hand hygiene is an important issue for both developed and developing countries.

Increasing hand hygiene compliance is a costeffective method in infection control. Research 
on hand hygiene adherence of health professionals has been conducted in several hospitals in Vietnam; however, very few were written in English and published in international journals [4-6]. Given the importance of hand hygiene procedure on patient health, this quality improvement project aimed to evaluate the compliance of hand washing and alcohol based hand rubbing (ABHR) in the Pediatric Department of Quang Tri General Hospital (QTGH).

\section{SUBJECTS AND METHODS}

\subsection{Study Site}

Quang Tri General Hospital (QTGH) is a newly renovated secondary care health facility in a very limited resource area of Quang Tri province, which is on the north central coast region of Vietnam, about $80 \mathrm{~km}$ north of the former imperial capital of Hue. The Pediatric Department has 32 staff members, including 8 physicians and 24 nurses, working across 5 floors for the inpatient units and 1 outpatient clinic.

The project was approved by the Board of Director of Quang Tri General Hospital and the Pediatric Department. There were two-hand hygiene procedures implemented in the department: hand washing (soap and water) and ABHR. The hand washing guideline instituted by the Vietnamese Health Department was based on the World Health Organization (WHO) guidelines. It included 6 steps (Figure1)and outlined the 5 moments to perform hand washing, including: 1 . before touching a patient, 2. before procedures, 3. after a procedure or body fluid exposure risk, 4. after touching a patient, 5. after touching a patient's surroundings. The ABHR guideline was instituted by $\mathrm{WHO}[7]$.

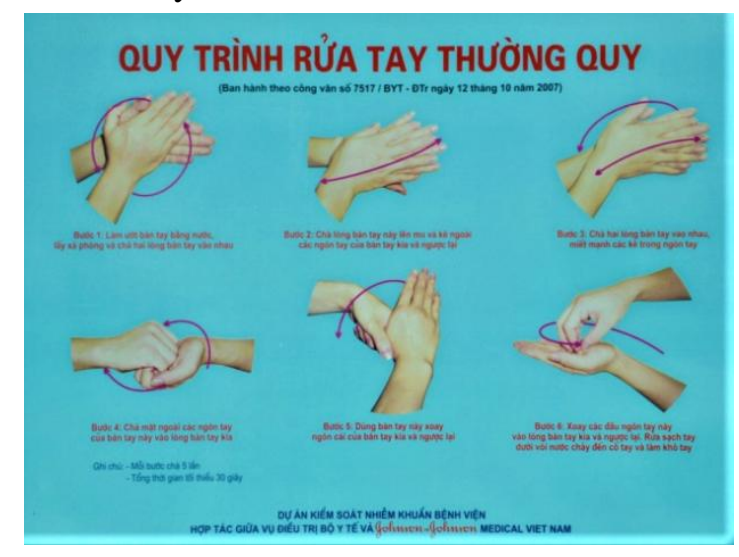

Figure1.Washing Hand Protocol (instructions printed in Vietnamese) posted over the Neonatal Intensive Care Unit sink

\subsection{Figure Legend}

\section{Left to right, top to bottom}

Step1. Wet your hands with water and rub with soap.

Step2. Use one palm to clean the back of the other hand, making sure to get in between the fingers, and then switch hands.

Step3. Rub your two palms against each other and make sure to get in between your fingers.

Step4. Scrub the outside of your fingers against the palm of the other hand and switch.

Step5. Use one hand and twist it around the thumb of the other hand to clean it. Make sure to switch hands.

Step6. Clean your fingertips in a drilling motion on the palm of the other hand. Make sure to switch hands. Rinse your hands clean under running water up to your wrists, and then dry your hands.

Note: Each step should include 5 scrubs. Minimum time is 30 seconds.

During three days of the study, we observed the hand hygiene compliance from the health care staff across three different settings of the Pediatric Department: the neonatal intensive care unit (NICU), outpatient clinic, and inpatient wards, including pediatric emergency room $\left(1^{\text {st }}\right.$ floor), neonatal care $\left(2^{\text {nd }}\right.$ floor $)$, pediatric care for GI complications ( $3^{\text {rd }}$ floor), and pediatric care for respiratory complications $\left(4^{\text {th }}\right.$ and $5^{\text {th }}$ floor). Each staff member was given three opportunities to demonstrate proper hand hygiene after each of the five moments mentioned above. A complete action was recorded only if the individual followed all the steps required by the specific guideline, i.e., hand washing or ABHR.

A self-reported survey about the staff's attitude and perception on hand hygiene procedures was conducted at the end of the week based on a questionnaire designed by Children's Hospital 2 in Ho Chi Minh City, Vietnam. A total of 6 physicians and 16 nurses were surveyed, including 2 males and 20 females. Of those observed, 2 completed postgraduate educations, 15 completed college, and 5 fell in other post high school education categories. Complete demographics of the staff are presented in Table 1. 
Table1. Demographics summary of the 22 health care staff at Pediatric Department

\begin{tabular}{|c|c|c|}
\hline \multicolumn{3}{|c|}{ Title } \\
\hline Physicians & 6 & $27 \%$ \\
\hline Nurses & 16 & $73 \%$ \\
\hline \multicolumn{3}{|c|}{ Gender } \\
\hline Male & 2 & $9 \%$ \\
\hline Female & 20 & $91 \%$ \\
\hline \multicolumn{3}{|c|}{ Education } \\
\hline Postgraduate & 2 & $9 \%$ \\
\hline Undergraduate & 15 & $68 \%$ \\
\hline Others - post high school & 5 & $23 \%$ \\
\hline \multicolumn{3}{|c|}{ Hand hygiene training } \\
\hline At hospital & 19 & $86 \%$ \\
\hline At school & 2 & $9 \%$ \\
\hline No training & 1 & $5 \%$ \\
\hline
\end{tabular}

\subsubsection{Hand Hygiene Compliance Audit}

Units observed in the Pediatric Department included the NICU, the outpatient clinic, and the inpatient wards. Alcohol based solution was readily available at each incubator in the NICU and on the physician's desk in the outpatient clinic. These solutions were only present in the immunization rooms on the $3^{\text {rd }}$ and $4^{\text {th }}$ floor of the inpatient wards and not in the patient bed areas. In the NICU and outpatient clinic where hand rubbing alcohol was available, ABHR compliance was audited.

\subsubsection{Health Care Staff Perception and Attitude toward Hand Hygiene Compliance}

A self-reported survey was conducted to assess the understanding of the healthcare staff regarding the importance of hand hygiene. Additionally, suggestions were solicited by the same workers to improve compliance.

\section{Results}

\subsection{Hand Hygiene Compliance Audit}

Through three days when the observation was documented, the compliance rate of the NICU and outpatient clinic was $76 \%(19 / 25)$. Most ABHR opportunities were contributed by the outpatient physician $(\mathrm{n}=15)$, with compliance rate of $100 \%(15 / 15)$, whereas the NICU staff showed a compliance rate of only $40 \%$ (4/10). Compliance rate was $0 \%$ in the inpatient wards as no alcohol-based solution was available.

Sinks were available outside the NICU, inside the outpatient clinic, and inside the patient bathroom of each of the inpatient rooms. However, hand washing was only implemented before entering the NICU with a compliance rate of $100 \%$. No hand-washing incident was observed throughout the outpatient clinic, but ABHR was practiced between each patient. There was $0 \%$ compliance for both hand washing and ABHR in the inpatient wards.

\subsection{Health Care Staff Perception and Attitude toward Hand Hygiene Compliance}

The survey showed that all staff $(100 \%)$ was aware of the 5 important moments for hand hygiene procedures and the 6 steps in hand washing. Most staff reported that it was easy to get access to hand hygiene supply (95\%). More than $80 \%$ of the staff agreed that hand hygiene equipment should be available at the following locations: each bed, each room, emergency room, operation room, and restroom. Some suggestions from the staff on how to improve hand hygiene included: more supply (50\%), easier accessibility (14\%), more education on benefits and procedure $(64 \%)$, culturing bacteria on healthcare staff to raise awareness (14\%), and regular inspection with potential penalty (68\%). Complete survey results are reported in Table 2.

Table 2. Health care staff's education and attitude toward hand hygiene in the Pediatric Department

\begin{tabular}{|c|c|c|c|c|c|}
\hline \multicolumn{3}{|c|}{$\begin{array}{l}\text { Education on Hand } \\
\text { Hygiene Procedures }\end{array}$} & \multicolumn{3}{|l|}{ Attitude } \\
\hline $\begin{array}{l}\text { Awareness of } \\
5 \text { important } \\
\text { moments }\end{array}$ & 22 & $100 \%$ & $\begin{array}{l}\text { Perception } \\
\text { effective } \\
\text { prevention is }\end{array}$ & on & $\begin{array}{l}\text { how } \\
\text { ection }\end{array}$ \\
\hline $\begin{array}{l}\text { Awareness of } \\
\text { the } 6 \text { steps in } \\
\text { hand washing }\end{array}$ & 22 & $100 \%$ & Very effective & 17 & $77 \%$ \\
\hline $\begin{array}{l}\text { Other } \\
\text { moments * }\end{array}$ & \multicolumn{2}{|c|}{ important } & $\begin{array}{l}\text { Relatively } \\
\text { effective }\end{array}$ & 5 & $23 \%$ \\
\hline $\begin{array}{l}\text { Before } \\
\text { wearing } \\
\text { gloves }\end{array}$ & 18 & $82 \%$ & \multicolumn{3}{|c|}{$\begin{array}{l}\text { Belief in who would } \\
\text { benefit } *\end{array}$} \\
\hline $\begin{array}{l}\text { After } \\
\text { removing } \\
\text { gloves }\end{array}$ & 17 & $77 \%$ & Patient & 21 & $95 \%$ \\
\hline $\begin{array}{l}\text { Before contact } \\
\text { with food }\end{array}$ & 15 & $68 \%$ & $\begin{array}{l}\text { Family } \\
\text { member }\end{array}$ & 13 & $59 \%$ \\
\hline $\begin{array}{l}\text { Before going } \\
\text { home }\end{array}$ & 18 & $82 \%$ & $\begin{array}{l}\text { Non-family } \\
\text { member visitor }\end{array}$ & 7 & $32 \%$ \\
\hline $\begin{array}{l}\text { After using } \\
\text { restroom }\end{array}$ & 19 & $86 \%$ & $\begin{array}{l}\text { Healthcare } \\
\text { staff }\end{array}$ & 20 & $91 \%$ \\
\hline \multicolumn{3}{|c|}{$\begin{array}{l}\text { Ease } \\
\text { and Accessibility of } \\
\text { hand hygiene supply }\end{array}$} & $\begin{array}{l}\text { Hospital } \\
\text { environment }\end{array}$ & 12 & $55 \%$ \\
\hline Easy & 21 & $95 \%$ & Community & 12 & $55 \%$ \\
\hline $\begin{array}{l}\text { Relatively } \\
\text { easy }\end{array}$ & 1 & $5 \%$ & \multicolumn{3}{|c|}{$\begin{array}{l}\text { Can you follow hand } \\
\text { hygiene procedure } \\
100 \% \text { of the time }\end{array}$} \\
\hline
\end{tabular}




\begin{tabular}{|c|c|c|c|c|c|}
\hline \multicolumn{2}{|c|}{$\begin{array}{l}\text { Understanding } \\
\text { duration for } \\
\text { hygiene }\end{array}$} & \multirow[t]{2}{*}{$\begin{array}{r}\begin{array}{r}\text { of } \\
\text { hand }\end{array} \\
50 \%\end{array}$} & \multirow{2}{*}{\begin{tabular}{l|l|} 
Absolutely \\
possible
\end{tabular}} & \multirow{2}{*}{\begin{tabular}{|l|}
15 \\
7
\end{tabular}} & \multirow{2}{*}{$\begin{array}{l}68 \% \\
32 \%\end{array}$} \\
\hline 1 minute & 1 & & & & \\
\hline 30 seconds & 16 & $73 \%$ & \multicolumn{3}{|c|}{$\begin{array}{l}\text { Is it important to follow } \\
\text { the procedures }\end{array}$} \\
\hline 15 seconds & 3 & $14 \%$ & Absolutely yes & 18 & $82 \%$ \\
\hline N/A & 2 & $9 \%$ & Yes & 4 & $18 \%$ \\
\hline $\begin{array}{l}\text { Perception o } \\
\text { hand } \\
\text { equipment sho }\end{array}$ & $\begin{array}{l}\text { on } \\
\text { ould }\end{array}$ & $\begin{array}{l}\text { where } \\
\text { nygiene } \\
\text { be } *\end{array}$ & \multicolumn{3}{|c|}{ Reported side effects * } \\
\hline Each bed & 18 & $82 \%$ & Dry skin & 19 & $86 \%$ \\
\hline Each room & 20 & $91 \%$ & Dermatitis & 1 & $5 \%$ \\
\hline \begin{tabular}{|l|} 
Emergency \\
room
\end{tabular} & 20 & $91 \%$ & Normal & 4 & $18 \%$ \\
\hline $\begin{array}{l}\text { Operation } \\
\text { room }\end{array}$ & 21 & $95 \%$ & & & \\
\hline \begin{tabular}{|l|} 
Administration \\
room
\end{tabular} & 3 & $14 \%$ & & & \\
\hline Restroom & 18 & $82 \%$ & & & \\
\hline $\begin{array}{l}\text { Waiting } \\
\text { room }\end{array}$ & 4 & $18 \%$ & & & \\
\hline Hallway & \multicolumn{2}{|c|}{\begin{tabular}{|l|l|l|} 
& 8 & $36 \%$ \\
\end{tabular}} & & & \\
\hline $\begin{array}{l}\text { Suggested } r \\
\text { sinks to bed }\end{array}$ & & for & \multicolumn{3}{|c|}{$\begin{array}{l}\text { Suggested solution from } \\
\text { staff } *\end{array}$} \\
\hline 1 per 2 beds & 3 & $14 \%$ & More supply & 11 & $50 \%$ \\
\hline 1 per 3 beds & 4 & $18 \%$ & $\begin{array}{l}\text { Easier } \\
\text { accessibility }\end{array}$ & 3 & $14 \%$ \\
\hline 1 per 4 beds & 6 & $27 \%$ & $\begin{array}{l}\text { More education } \\
\text { on benefits and } \\
\text { procedure }\end{array}$ & 14 & $64 \%$ \\
\hline 1 per 5 beds & 6 & $27 \%$ & $\begin{array}{l}\text { Culture bacteria } \\
\text { on healthcare } \\
\text { staff's hands to } \\
\text { raise awareness }\end{array}$ & 3 & $14 \%$ \\
\hline N/A & 3 & $14 \%$ & $\begin{array}{l}\text { Regular } \\
\text { inspection with } \\
\text { potential } \\
\text { penalty }\end{array}$ & 15 & $68 \%$ \\
\hline
\end{tabular}

\subsection{Survey Of Cost and Demand of Hand Hygiene Supply at Quang Tri General Hospital}

For hand hygiene procedures, the hospital provides the department with alcohol based solutions and soap based on the number of beds (113 beds). Monthly, the department receives $3500 \mathrm{~mL}$ of alcohol based solution for hand rubbing ( $14 \times 250-\mathrm{mL}$ bottles), which costs 238 $000 \mathrm{VND}$ or approximately 10 USD (14 x 17 $000 \mathrm{VND} /$ bottle). In addition, the department is provided with 10 bottles of hand soap $(180 \mathrm{~mL}$ each) for hand washing, which costs 260000 VND or approximately 12 USD in total (10 x 26 $000 \mathrm{VND} /$ bottle). This number does not generally meet the need of the staff due to the high volume of patients, thus the department often requests for extra supplies. The baseline need of the department is 13 bottles of hand soap per month (based on the number of the patients), requiring the department to request for an additional 3 bottles of hand soaps per month. It is evident that the amount of supply calculated based on the number of bed cannot meet the demand based on the volume of patients treated by the department per month. Once the number of admitted patients increases, the hospital provides the department with an additional 5L of Micro shield 4\% solution, which costs 535 000 VND or approximately 25 USD, upon request from the department. The Micro shield solution is a type of hand soap that is intended for use in the scrub sinks. While the hand soap bottles are consumed within a month, the $5 \mathrm{~L}$ Micro shield generally lasts a couple of months. Evidently, as the number of admitted patients changes from month to month, the demand for hand hygiene supply also varies.

\section{DISCUSSION}

Hand hygiene is a fundamental component of hygienic patient-care, which can easily be overlooked. This quality improvement study assessed the compliance of hand hygiene procedures of the Pediatric Department in Quang Tri General Hospital. The result showed a total compliance rate of $76 \%$ to ABHR in the NICU and outpatient clinic, excluding noncompliance incidence in the inpatient wards, where supplies were not available. The outpatient clinic showed $100 \%$ compliance rate during the mornings of observation, while the NICU showed only a $40 \%$ compliance rate. Alcohol based solution was conveniently located on the physician's desk, allowing for high compliance of ABHR. Therefore, poor compliance outside of the NICU and outpatient clinic could be explained by the lack of resources and accessibility for healthcare staff. Besides ABHR, hand washing was implemented only in the NICU as a required procedure before entering the NICU. Health care staff was required to wash their hands according to the guidelines posted above the sink (see Figure 1) in addition to changing footwear before entering the NICU room. On the other hand, the inpatient wards did not have sinks or alcohol based solutions readily available for medical staff to access, which could explain the lack of compliance in these areas. 
The survey results indicated that half the staff suggested an increase in supplies to improve compliance. This view was demonstrated through the monthly additional request from the department for extra alcohol rub solution and hand soap as the volume of patients in the department increased. Interestingly, only $14 \%$ of the staff recognized that accessibility to hand hygiene procedures posed a barrier to compliance, despite the fact that we had observed no hand rubbing alcohol solutions and accessible sinks in the inpatient wards. This discrepancy in the staff's perception and the current situation remains to be further evaluated.

A similar study done at Hue General Hospital in 2010 showed an overall compliance of $47 \%$ [8]. The significant higher compliance rate observed in the Pediatric Department of Quang Tri General Hospital could be explained by multiple reasons. Firstly, the subjects in the study were exposed to observer bias (Hawthorne Effect) whereby the subjects modify their behaviors in response to being observed. All subjects were made aware that their hand hygiene procedures would be observed by medical students at the beginning, and hence had probably increased their compliance. Secondly, the observations at Quang Tri General Hospital were limited to where the hand rubbing resources were available (i.e., the NICU and outpatient clinic). Had all interactions between healthcare staff and patients in the inpatient wards been observed and documented, the compliance rate may have been significantly lower. Lastly, the sample sizes at Quang Tri Hospital was much lower $(n=22)$ compared to Hue General Hospital $(\mathrm{n}=2250)$.

Taking the results of our study and the experience reported in the literature collectively, several areas for improvement become apparent as discussed below. It may be beneficial to install an alcohol-based solution at each patient bed or equip each healthcare staff with a portable alcohol based solution. These changes increase accessibility and encourage ABHR usage. Easier access, mobility, and less time investment make hand rubbing an efficient alternative to hand washing. Given that the pediatric department is often crowded with young children, installing alcohol-based solution at each bed could be hazardous when there is no adult supervision. There is also risk of misuse by family members, potentially increasing cost for the hospital. As a result, it would be more practical and economical to provide each healthcare staff in the department with a portable alcohol based system, which they could use anytime.

Despite the convenience of ABHR, there are benefits from hand washing that cannot be replaced. ABHR cannot effectively eradicate Clostridium difficile[9], an anaerobic spore forming bacteria that has been shown to cause diarrhea and contribute to hospital acquired disease in

Asia [10-13].Clostridium difficile can spread through feces by hand-to-mouth contact, and its spores can also contaminate surfaces; thus, poor hand hygiene will lead to Clostridium difficile infection through this manner. Jabbaret al showed that hand washing was significantly more effective at removing Clostridium difficile spores, while offering no statistical difference between hand rubbing with alcohol and hand rubbing with plain water[14].Shaking another person's hand following hand rubbing with alcohol also led to a transfer of $30 \%$ of residual spore to the recipient, showing easy transmission of Clostridium difficile from person to person. Furthermore, overuse of antibiotics in developing countries, such as Vietnam, has been a major and often neglected concern that contributed to antimicrobial resistance [15-17] and has rendered ABHR even less effective in preventing Clostridium difficile infection. Unfortunately, the association between Clostridium difficile with diarrhea and Clostridium difficile studies involving Asia remain sparse[18, 19].Recalling the situation in QTGH, where ABHR remained the popular choice for hand hygiene and hand washing compliance was substantially low outside of NCIU, the risk of Clostridium difficile infection cannot be overlooked and should be evaluated.

From our observation, barriers at QTGH that prevent compliance to hand washing involved the lack of accessibility to sinks and hand soap. A study in the United States found an increased compliance of hand washing following interaction with patient with Clostridium difficile infection when the sinks were closer to the patients' rooms [20]. Hence, one solution to increase hand-washing compliance at QTGH consists of installing more sinks in the patient bed areas, where the health care staff could easily access them. Presently, for each patient room in the inpatient ward (7-10 beds/room), there is only one sink located in the patient bathroom for the patients and their family 
members to use. Increasing the health care staff's access to sink in each patient room should be of interest for future quality improvement measures at QTGH, to improve hand-washing compliance and to prevent possible outbreak of Clostridium difficile infection.

Frequent audits on hand hygiene procedure could also increase compliance. The University of Wisconsin Hospital (UWH) has established a system to audit 100 health care workers per month. Before 2012, the average compliance of hand washing for UWH was around $68 \%$. With a program that implemented audits and rewards for units with top compliance rates, the compliance rose dramatically and averaged $96 \%$ for two years (unpublished data provided by the University of Wisconsin Nursing Program of Development and Evaluation-Quality and Safety).Similar observations were seen with frequent survey and educational promotion for hand hygiene at another hospital in Vietnam[4, 6]. Relative to such observations, a survey of the staff at QTGH indicated $68 \%$ of the staff believed that more audits (inspections) along with penalties for noncompliance would improve compliance. Given the success of an established program as a reference and the staff's belief at QTGH, frequent audits with appropriate penalties or reward are a promising method for future improvement of hand hygiene compliance.

Clearly, our study has several limitations. Hand hygiene compliance was observed only in one department, of a single hospital. This result certainly does not reflect the compliance rate of the whole hospital. Therefore, it would be crucial to perform more in-depth analysis across multiple departments, thus, overcoming the limitations of sample size. Moreover, observation was performed only where supplies were available in the Pediatric Department, so hand compliance could have been different had the resources been available across the different levels of care, i.e., NICU, inpatient wards, and outpatient clinic. In addition, the survey was self-reported and broad. For example, 23\% of the staff felt that hand hygiene was only relatively effective at preventing infection; however, we could not survey in depth the staff's opinions. A better understanding of the staff's attitudes would be important to improve future hand hygiene education and implementation. Therefore, in-depth and focus group interviews could be more beneficial in this regard.

\section{CONCLUSION}

In summary, we observed an overall compliance rate of $76 \%$ to $\mathrm{ABHR}$ in the Pediatric Department of Quang Tri General Hospital. Hand washing was only practiced before entering the NICU. Our survey indicated a good understanding of all the staff on hand hygiene procedure; however, the current lack of supply and accessibility to hand hygiene tools prevented the staff from improving their compliance. Looking forward, the department may improve compliance by: i) supplying each health care staff with portable alcohol based solution and hand moisturizer, ii) conducting more frequency inspections on their staff, and iii) investing into installing more accessible sinks for hand washing practice.

\section{ACKNOWLEDGEMENT}

We thank the Pediatric Department of Quang Tri Hospital for allowing us to conduct this study and their cooperation throughout the process.

\section{REFERENCE}

[1] Kohn L.T., Corrigan J., Donaldson M.S., Institute of Medicine (U.S.). Committee on Quality of Health Care in America. To err is human : building a safer health system. Washington, D.C.: National Academy Press; (2000).

[2] Pittet D., Improving adherence to hand hygiene practice: a multidisciplinary approach. Emerg Infect Dis, 7(2), 234-40 (2001).

[3] Rosenthal V.D., Maki D.G., Salomao R., Moreno C.A., Mehta Y., Higuera F., et al., Device-associated nosocomial infections in 55 intensive care units of 8 developing countries. Ann Intern Med, 145(8), 582-91 (2006).

[4] Thi Anh Thu L., Thi Hong Thoa V., Thi Van Trang D., Phuc Tien N., Thuy Van D., Thi Kim Anh L., et al., Cost-effectiveness of a hand hygiene program on health care-associated infections in intensive care patients at a tertiary care hospital in Vietnam. Am J Infect Control, 43(12), e93-9 (2015).

[5] Nguyen K.V., Nguyen P.T., Jones S.L., Effectiveness of an alcohol-based hand hygiene programme in reducing nosocomial infections in the Urology Ward of Binh Dan Hospital, Vietnam. Trop Med Int Health, 13(10), 1297302 (2008).

[6] Hang P.T., Hang T.T.T., Anh D.P.P., Zingg W., Pittet D., Effectiveness after 5 years of the who 
hand hygiene promotion strategy to reduce health-care-associated infections at Hung Vuong Hospital, Vietnam. Antimicrobial Resistance and Infection Control, 4(Suppl 1), O20-O (2015).

[7] World Health Organization. Patient Safety. WHO guidelines on hand hygiene in health care : first global patient safety challenge clean care is safer care. Geneva: World Health Organization, Patient Safety,; p. 1 online resource ( PDF file (v, 262 pages)) (2009.)

[8] Salmon S., Tran H.L., Bui D.P., Pittet D., McLaws M.L., Beginning the journey of hand hygiene compliance monitoring at a 2,100-bed tertiary hospital in Vietnam. Am J Infect Control, 42(1), 71-3 (2014).

[9] Vonberg R.P., Kuijper E.J., Wilcox M.H., Barbut F., Tull P., Gastmeier P., et al., Infection control measures to limit the spread of Clostridium difficile. Clin Microbiol Infect, 14 Suppl 52-20 (2008).

[10] Borriello S.P., 12th C. L. Oakley lecture. Pathogenesis of Clostridium difficile infection of the gut. J Med Microbiol, 33(4), 207-15 (1990).

[11] Borriello S.P., Pathogenesis of Clostridium difficile infection. J Antimicrob Chemother, 41 Suppl C13-9 (1998).

[12] Poxton I.R., McCoubrey J., Blair G., The pathogenicity of Clostridium difficile. Clin Microbiol Infect, 7(8), 421-7 (2001).

[13] Barbut F., Petit J.C., Epidemiology of Clostridium difficile-associated infections. Clin Microbiol Infect, 7(8), 405-10 (2001).
[14] Jabbar U., Leischner J., Kasper D., Gerber R., Sambol S.P., Parada J.P., et al., Effectiveness of alcohol-based hand rubs for removal of Clostridium difficile spores from hands. Infect Control Hosp Epidemiol, 31(6), 565-70 (2010).

[15] Nga do T.T., Chuc N.T., Hoa N.P., Hoa N.Q., Nguyen N.T., Loan H.T., et al., Antibiotic sales in rural and urban pharmacies in northern Vietnam: an observational study. BMC Pharmacol Toxicol, 156 (2014).

[16] Thompson C.N., Phan M.V., Hoang N.V., Minh P.V., Vinh N.T., Thuy C.T., et al., A prospective multi-center observational study of children hospitalized with diarrhea in Ho Chi Minh City, Vietnam. Am J Trop Med Hyg, 92(5), 1045-52 (2015).

[17] World Health Organization. Antimicrobial resistance : global report on surveillance 2014. Geneva: World Health Organization; (2014).

[18] Collins D.A., Hawkey P.M., Riley T.V., Epidemiology of Clostridium difficile infection in Asia. Antimicrob Resist Infect Control, 2(1), 21 (2013).

[19] Ekma N., Yee L.Y., Aziz R.A., Prevalence of Clostridium difficile infection in Asian countries. Reviews in Medical Microbiology, 23(1), 1-4 (2012).

[20] Deyneko A., Cordeiro F., Berlin L., Ben-David D., Perna S., Longtin Y., Impact of sink location on hand hygiene compliance after care of patients with Clostridium difficile infection: a cross-sectional study. BMC Infect Dis, 16203 (2016).

Citation: Kevin B. H. Vo, HuyTram N. Nguyen, Binh Doan, Quynh Kieu \& H. Ian Robins. Challenges Encountered in Compliance to Hand Hygiene in the Pediatric Department of a Hospital in Central Vietnam. ARC Journal of Public Health and Community Medicine.2017; 2(4):1-7: dx.doi.org/10.20431/ 24560596.0204001

Copyright: (C) 2017 Authors. This is an open-access article distributed under the terms of the Creative Commons Attribution License, which permits unrestricted use, distribution, and reproduction in any medium, provided the original author and source are credited. 